\title{
Protective effect of pre-recovery surfactant inhalation on lungs donated after cardiac death in a canine lung transplantation model.
}

\section{AUTHOR(S):}

Ohsumi, Akihiro; Chen, Fengshi; Sakamoto, Jin; Nakajima, Daisuke; Hijiya, Kyoko; Motoyama, Hideki; Okita, Kenji; ... Yamada, Tetsu; Bando, Toru; Date, Hiroshi

\section{CITATION:}

Ohsumi, Akihiro ...[et al]. Protective effect of pre-recovery surfactant inhalation on lungs donated after cardiac death in a canine lung transplantation model.. The Journal of heart and lung transplantation 2012, 31(10): 1136-1142

\section{ISSUE DATE:}

2012-10

\section{URL:}

http://hdl.handle.net/2433/160383

\section{RIGHT:}

(C) 2012 International Society for Heart and Lung Transplantation. Published by Elsevier Inc.; この論文は出版社版でありません。引用の際には出版社版をご確認ご利用ください 。; This is not the published version. Please cite only the published version. 
Protective effect of prerecovery surfactant inhalation on lungs donated after cardiac death in a canine lung transplantation model

Akihiro Ohsumi, MD, Fengshi Chen, MD, PhD, Jin Sakamoto, MD, Daisuke Nakajima, MD, Kyoko Hijiya, MD, Hideki Motoyama, MD, Kenji Okita, MD, Kenta Horita, Ryutaro Kikuchi, MD, Tetsu Yamada, MD, Toru Bando, MD, PhD, and Hiroshi Date, MD, PhD

Department of Thoracic Surgery, Graduate School of Medicine, Kyoto University, Kyoto, Japan

\section{Address correspondence to:}

Hiroshi Date

Mailing address: 54 Shogoin-Kawahara-cho, Sakyo-ku, Kyoto 606-8507, Japan

Telephone number: +81 757514975 (business), +81 754688979 (home)

Fax: +81 757514974 (business), +81 754688979 (home)

E-mail: hdate@kuhp.kyoto-u.ac.jp

Reprint requests: Hiroshi Date, MD, PhD, 54 Shogoin-Kawahara-cho, Sakyo-ku, Kyoto 606-8507, Japan. Telephone: +81 75751 4975. Fax: +81 75751 4974. E-mail: hdate@kuhp.kyoto-u.ac.jp 


\section{Abstract}

Background: Warm ischemia-reperfusion injury related to donation after cardiac death is a crucial issue in transplantation. Since surfactant function deteriorates in lungs during warm ischemia, we hypothesized prerecovery surfactant inhalation would mitigate warm ischemia-reperfusion injury.

Methods: We rendered donor dogs cardiac dead and left them at room temperature. All animals received ventilation for 60 min starting at 240 min after cardiac arrest. The animals were divided into 2 groups: NS (Normal saline) and SF (Surfactant). The NS group $(n=7)$ and SF group $(n=5)$ received aerosolized normal saline and aerosolized surfactant, respectively. The lungs were flushed, procured, and then the left lung was transplanted into recipient dogs. At 45 min of reperfusion, the right pulmonary artery was ligated, and the left transplanted lung function was evaluated.

Results: In the NS group, 2 of 7 died at 75 min after reperfusion, whereas all 5 animals in the SF group survived for 240 min after reperfusion. The SF group showed significantly better dynamic compliance, oxygenation, and wet-to-dry weight ratio. Furthermore, the SF group had higher levels of high-energy phosphates in the lung tissues and lower levels of IL-8, TNF-a, and protein in the bronchoalveolar lavage fluid. Histologically, the lungs in the SF group showed fewer signs of interstitial edema and hemorrhage and significantly less neutrophilic sequestration than those of the NS group.

Conclusions: Our results indicated prerecovery surfactant inhalation improved graft function, maintained adenine nucleotide levels, and prevented alveolar-capillary barrier leakage, resulting in the attenuation of warm 
ischemia-reperfusion injury.

\section{Introduction}

To deal with the shortage of donor organs in lung transplantation, donation after cardiac death (DCD) has been introduced worldwide as one of the potential strategies to increase the donor pool. Steen et al. first successfully performed lung transplantation from uncontrolled DCD donors in 2000. ${ }^{1}$ Since then, several programs have reported acceptable outcomes comparable to donation after brain death. ${ }^{2,3}$ However, there has been a progressive increase in the number of patients on the waiting list, which continually exceeds the number of available organs.

Warm ischemia inevitably occurs in DCD donors after cardiac arrest and may cause ischemia-reperfusion (I-R) injury after transplantation. The acceptable period of warm ischemia is short, ${ }^{4}$ thus limiting the frequency of lung transplantation from uncontrolled DCD donors. Therefore, the inhibition of warm I-R injury is crucial to facilitating lung transplantation from uncontrolled DCD donors. ${ }^{5}$

In DCD donors, intravenous drug administration is difficult, since the circulation has stopped. However, inhalation appears to be not only suitable and convenient for drug administration but offers a lung-specific drug delivery route. ${ }^{6,7}$ Moreover, our previous experiments using drug inhalation in warm ischemic-reperfused rat lungs have been successful. ${ }^{6,7}$

A pulmonary surfactant mostly comprises phospholipids and surfactant proteins (SP-A, -B, -C, and -D), and forms a monolayer at the air-lipid interface, reducing the surface tension in the alveoli. This mechanism prevents alveolar collapse $^{8,9}$ and protects the lung. 
Although surfactants have been used as a therapy for ARDS, exogenous surfactant might improve oxygenation but did not improve mortality in most reports. ${ }^{10-12}$ Davidson et al. stated the potential explanation: patients with ARDS usually die of multi-organ system failure from their underlying disease process rather than from respiratory failure per se: the proper 'surfactant recipe' had not yet been found, that is, a dose, formulation, and delivery strategy of surfactant that could be effective. ${ }^{11}$ Thus, surfactant administration for ALI and ARDS has not been established as a standard therapy.

Surfactants have been administered in clinical settings to patients with severe primary graft dysfunction after transplantation ${ }^{13,14}$ and for donor lungs. ${ }^{15}$ Recently, surfactant function was reported to deteriorate with increasing warm ischemic time intervals $^{9}$; however, to date, no study has been conducted on the protective effect of surfactant administration against pulmonary warm I-R injury. Therefore, we examined the protective effect of surfactant administration in marginal donor grafts from uncontrolled DCD donors in a canine lung transplantation model.

\section{Materials and Methods}

\section{Animals}

Twelve pairs of weight-matched TOYO Beagles (9.75-11.05 kg, Kitayama Labes Co. Ltd., Hongo Farm, Yamaguchi, Japan) were used in this study. All animals received humane care in compliance with the Principles of Laboratory Animal Care, which was formulated by the National Society for Medical Research, and the Guide for the Care and Use of Laboratory Animals, prepared by the Institute of Laboratory Animal Resources and published by the National Institutes of Health (NIH 
publication no. 86-23, revised 1996). The study protocol was approved by the ethics committee of the Graduate School of Medicine at Kyoto University, Japan.

\section{Surfactant and Aerosol Delivery}

In this study, we used beractant (Surfacten ${ }^{\circledR}$, Mitsubishi Tanabe Pharma Corporation, Osaka, Japan). Beractant is a natural bovine lung extract containing phospholipids, neutral lipids, fatty acids, and the 2 surfactant-associated proteins SP-B and SP-C. A 30-mg/mL surfactant solution was obtained by dissolving Surfacten ${ }^{\circledR}$ with normal saline $(0.9 \%)$. The surfactant was aerosolized by a nebulizer (AGAL1000, Aerogen, Ireland) and placed in the inspiratory loop of the ventilator. In this system, the diameters of $\sim 90 \%$ and $\sim 60 \%$ of the aerosolized particles were maintained below $10 \square \mathrm{m}$ and $3.0 \square \mathrm{m}$, respectively.

\section{Donor Preparation}

The operative technique was previously reported. ${ }^{16}$ Donor dogs were anesthetized by an intramuscular injection of midazolam $(0.5 \mathrm{mg} / \mathrm{kg})$, xylazine $(0.25 \mathrm{mg} / \mathrm{kg})$, and atropine sulfate $(0.05 \mathrm{mg} / \mathrm{kg})$. The animals were then intubated and mechanically ventilated at a tidal volume of $25 \mathrm{~mL} / \mathrm{kg}$ and a respiration rate of $15 \mathrm{breaths} / \mathrm{min}$. The positive end-expiratory pressure was $5.0 \mathrm{cmH}_{2} \mathrm{O}$; the inspired $\mathrm{O}_{2}$ fraction was 1.0. The donors were maintained at an inhalation of $1 \%$ to $2 \%$ sevoflurane and an intravenous injection of vecuronium bromide $(0.4 \mathrm{mg} / \mathrm{kg} / \mathrm{hr})$. They were euthanized by an intravenous administration of potassium chloride $(0.5 \mathrm{mEq} / \mathrm{kg})$, without heparinization. The ventilators were removed, and the tracheal tubes were open to room air. All donors were left at room temperature $\left(21^{\circ} \mathrm{C}\right)$ for $240 \mathrm{~min}$ and 
subsequently received ventilation with $100 \%$ oxygen for 60 min starting at $240 \mathrm{~min}$ after cardiac arrest. The animals were divided into a NS (Normal saline) group and a SF (Surfactant) group. During this ventilation period, the NS group $(n=7)$ received $8 \mathrm{~mL}$ of aerosolized normal saline, while the $\mathrm{SF}$ group $(\mathrm{n}=5)$ received aerosolized surfactant: $240 \mathrm{mg}$ of surfactant dissolved in $8 \mathrm{~mL}$ of normal saline was loaded. A pulmonary arterial flush was performed on all donors at $300 \mathrm{~min}$ after the cardiac arrest, using ET-Kyoto solution (Otsuka Pharmaceutical Factory Inc., Tokushima, Japan), an extracellular preservation solution that we originally developed for clinical lung transplantation. ${ }^{17}$ For the antegrade flush, we used 100 $\mathrm{mL} / \mathrm{kg}$ of this solution; $50 \mathrm{~mL} / \mathrm{kg}$ was used for the retrograde flush (temperature $4^{\circ} \mathrm{C}$; pressure, $\left.30 \mathrm{cmH}_{2} \mathrm{O}\right)$. Ventilation was performed during the flush. The recovered organs, semi-inflated with $100 \%$ oxygen, were preserved at $4^{\circ} \mathrm{C}$ for 2 hours.

\section{Recipient Preparation and Transplantation}

Recipient dogs were anesthetized, maintained, and ventilated in the same manner as the donors. Peak inspiratory pressure was monitored by a pressure transducer attached to the tracheal tube. For each recipient, a 5-F thermodilution catheter (151 F7, Edwards Lifesciences, Irvine, CA) was placed in the main pulmonary artery from the right femoral vein to measure pulmonary arterial pressure, central venous pressure, and cardiac output. A femoral arterial line was inserted for measuring arterial pressure and for arterial blood gas analysis. We then performed a left pneumonectomy and left lung transplantation. We set 60 min for the implantation time. After reperfusion, a $2.0-\mathrm{mm}$ catheter was inserted directly into the left atrium 
for monitoring left arterial pressure. The right pulmonary artery was encircled with vascular tape and clamped with a tourniquet at $45 \mathrm{~min}$ after reperfusion to evaluate the function of the transplanted left lung. After the right pulmonary artery was clamped, the right main bronchus was also encircled with vascular tape and intermittently clamped to evaluate the pulmonary dynamic compliance of the transplanted left lung.

\section{Physiological Data Analysis}

The pulmonary shunt fraction $\left(Q_{\mathrm{s}} / Q \mathrm{t}(\%)\right)$ was calculated according to the following formula: $Q \mathrm{~s} / Q \mathrm{t}(\%)=(C \mathrm{c}-C \mathrm{a}) /(C \mathrm{c}-C \mathrm{v}) \times 100$, where $C \mathrm{c}, C \mathrm{a}$, and $C \mathrm{v}$ represent the oxygen content of the pulmonary capillary, artery, and venous blood, respectively. The pulmonary dynamic compliance $\left(\mathrm{mL} / \mathrm{cmH}_{2} \mathrm{O}\right)$ was defined as tidal volume/[peak airway pressure - positive end-expiratory pressure]. The pulmonary dynamic compliance of the transplanted left lung was defined as half of the tidal volume/[peak airway pressure - positive end-expiratory pressure]. Arterial and pulmonary arterial blood samples were taken to analyze blood gases with a blood gas analyzer (iSTAT Portable Clinical Analyzer; iSTAT Corp., East Windsor, NJ).

\section{Wet-to-Dry Weight Ratio (WDR)}

Left lung tissues (1000-2000 mg) were used to calculate the WDR at $240 \mathrm{~min}$ after reperfusion or at death. The tissues were excised from the tip of the ventral side of the lung, and the cut end was closed by ligation. The wet weight (mg) was measured first; the dry weight (mg) was measured after the tissue had been dried overnight at $180^{\circ} \mathrm{C}$. The WDR was calculated by dividing the wet weight by the dry weight. 


\section{Bronchoalveolar Lavage (BAL)}

After the collections for the other investigations had been conducted, the lavage of the transplanted left lung was performed via fiberoptic bronchoscopy with $30 \mathrm{~mL}$ of normal saline. Recovery was approximately $15 \mathrm{~mL}$ in all experiments. The lavage was centrifuged, and the supernatant was stored $-80^{\circ} \mathrm{C}$ until measurements.

\section{Measurement of Adenine Nucleotide Levels}

We used the pieces of peripheral lung tissues collected from donors before and after inhalation and from recipients at $240 \mathrm{~min}$ after reperfusion. We measured lung tissue levels of ATP, ADP, AMP, and total adenosine nucleotides (TAN; TAN = ATP + $\mathrm{ADP}+\mathrm{AMP}$ ) using high-performance liquid chromatography (Shim-pack CLC-ODS column; $15 \mathrm{~cm} \times 6.0 \mathrm{~mm}$; Shimadzu, Japan).

\section{Cytokine Levels in BAL Fluid}

We used IL-6, IL-8, and TNF-a enzyme-linked immunosorbent assays (ELISAs) kits (Quantikine, R\&D Systems Inc., Minneapolis, MN) to measure the respective levels of these proteins in BAL fluid at 4 hours after reperfusion.

\section{BAL Protein Levels}

Protein concentrations in $10 \square \mathrm{L}$ of BAL was determined by a protein assay (Bio-Rad Laboratories, Hercules, CA, USA) with bovine serum albumin as a standard.

\section{Myeloperoxidase (MPO) Activity}


The level of MPO was measured in the left lung of each of the studied lungs, which were collected at 240 min after reperfusion and snap frozen in liquid nitrogen until the assays were performed. MPO activity ( $\square \mathrm{U} / \mathrm{mg}$ wet weight; $\mathrm{U}=\square \mathrm{mol} / \mathrm{min}$ ) was measured with an MPO Assay Kit (BioVision Research Products, Mountain View, CA, USA), according to the manufacturer's instructions, and defined as the sample measurement / [incubation time $\times$ sample volume] .

\section{Macroscopic Figures and Histology}

We recorded the macroscopic appearances of the left lungs 4 hours after reperfusion. Left lung specimens obtained 240 min after reperfusion were used for histologic analysis. Each lung was immersed in $10 \%$ formalin, embedded in paraffin, and stained with hematoxylin-eosin (H-E).

\section{Statistical Analyses}

All statistical analyses were performed using STATVIEW v5.0 (Abacus Concepts Inc., Berkeley, CA). Values are expressed as the mean \pm the standard deviation. We used Mann-Whitney $U$ tests and repeated-measures analysis of variance tests to explore differences between and within treatment groups. Significance was defined as a $\mathrm{p}$ value less than 0.05 .

\section{Results}

No significant differences were observed between the 2 experimental groups in terms of the donor or recipient weights (NS group vs. SF group, donor weight: $10.2 \pm$ $0.3 \mathrm{~kg}$ vs. $10.5 \pm 0.3 \mathrm{~kg}$; recipient weight: $9.2 \pm 0.4 \mathrm{~kg}$ vs. $9.4 \pm 0.4 \mathrm{~kg}$ ). We were able 
to perform the implantation within $60 \mathrm{~min}$. All 5 animals in the SF group survived until the endpoint of the study (240 min after reperfusion), whereas only 5 of 7 in the NS group survived. Two animals died of graft dysfunction at 75 min after reperfusion.

\section{Assessment of Pulmonary and Cardiac Function}

In both groups, the dynamic compliance of the donor's bilateral lungs was compared before and after inhalation by the paired t-test. In the NS group, no differences were observed before and after inhalation $\left(18.4 \pm 6.2\right.$ and $18.7 \pm 5.9 \mathrm{ml} / \mathrm{cmH}_{2} \mathrm{O}$, respectively; $\mathrm{p}=0.69$ ). However, in the $\mathrm{SF}$ group, the dynamic compliance was significantly higher after inhalation (before inhalation vs. after inhalation: $16.9 \pm$ 3.7 vs. $25.0 \pm 5.3$, respectively; $p=0.0055)$. Moreover, the dynamic compliance of the recipient's bilateral lungs in the SF group was higher just prior to reperfusion, with this difference reaching significance $(p=0.0003$; Table 1$)$. The dynamic compliance of the recipient's transplanted left lung in the SF group was also higher after clamping of the right pulmonary artery, and this difference also reached significance $(p=0.031)$. The $\mathrm{PaO}_{2}$ at 240 min after reperfusion was significantly lower in the NS group $(64.0 \pm 15.0 \mathrm{mmHg})$ than that in the $\mathrm{SF}$ group $(547.8 \pm 96.2$ mmHg; $p=0.0022$ ), while no difference in the $\mathrm{PaCO}_{2}$ was observed between the 2 groups $(p=0.27)$. Furthermore, the shunt fraction and the differences in the alveolar-arterial oxygen pressure $\left(\mathrm{A}-\mathrm{aDO}_{2}\right)$ were significantly lower in the SF group than those in the NS group $(p=0.0078$ and $p=0.0017$, respectively). The pulmonary vascular resistance and the cardiac output seemed low and high, respectively, in the SF group; however, neither these of parameters nor the mean 
pulmonary artery pressure was significantly different between the two groups (Table 1).

\section{$W D R$}

The WDR at 240 min after reperfusion was significantly lower in the SF group than that in the NS group ( $6.34 \pm 1.37$ vs. $11.98 \pm 3.27$, respectively; $\mathrm{p}=0.0090)$.

\section{Measurement of Adenine Nucleotide Levels}

Just after inhalation, the differences in the TAN, ATP, ADP, and AMP levels between the NS and SF groups did not reach significance (Figure 1A). However, at 240 min after reperfusion in the SF group, the TAN and ATP levels increased, so that the TAN, ATP, and ADP levels were significantly higher than those in the NS group (TAN: $p=0.016$, ATP: $p=0.016$, ADP: $p=0.047$; Figure 1B).

\section{Cytokine Levels in BAL fluid}

At 240 min after reperfusion, IL-8 and TNF- $\alpha$ levels in the BAL fluid were significantly lower in the SF group than those in the NS group $(p=0.0090$ and 0.016 , respectively; Figure 2A-C).

\section{Protein Concentration in BAL Fluid}

At 240 min after reperfusion, the protein concentration in BAL was significantly lower in the SF group than that in the NS group (NS group vs. SF group: $1.47 \pm 0.50$ vs. $0.68 \pm 0.16 \mathrm{mg} / \mathrm{mL} ; \mathrm{p}=0.0090)$. 


\section{MPO Activity}

MPO activity has been previously used as a marker for neutrophilic sequestration during acute inflammatory responses. ${ }^{6}$ At 240 min after reperfusion, the MPO activity was lower in the SF group than that in the NS group (NS group vs. SF group: $30.0 \pm 9.3$ vs. $11.6 \pm 7.2 \square \mathrm{U} / \mathrm{mg}$ wet weight; $\mathrm{p}=0.0090)$.

\section{Macroscopic Figures and Histology}

At 240 min after reperfusion, lungs from animals in the NS group had broad dark-red areas that showed more patchiness than that observed macroscopically in the SF group (Figure 3A, B). Histologically, in the NS group, mild to severe interstitial and alveolar edema was observed in almost all areas; moreover, severe interstitial and alveolar hemorrhage was sporadically observed (Figure 4A). However, in the SF group, only slightly interstitial edema was observed in alveoli (Figure 4B).

\section{Discussion}

In this study, we used a canine lung transplantation model to investigate the effect of surfactant inhalation on I-R injury in lungs from DCD donors. Our results showed that surfactant inhalation in the last phase of warm ischemia improved graft functions, prevented protein leakage into alveoli, and maintained adenine nucleotide levels, thereby attenuating warm I-R injury in canine lungs. This is the first study to report that surfactant inhalation during warm ischemia attenuated warm I-R injury of the lung in a large animal model.

Surfactant deficiency reduces the stability and patency of peripheral airways, ${ }^{18}$ 
leading to decreased lung compliance, atelectasis, ${ }^{19}$ and uneven distribution of inspired gas. ${ }^{20}$ In the current study, the dynamic compliance increased after surfactant inhalation in the SF group relative to that in the NS group. Further, the dynamic compliance was significantly higher in the SF group than that in the NS group and was maintained at a greater than baseline level until the end of the reperfusion period. Exogenous surfactant pretreatment reportedly improved lung compliance and gas exchange with beneficial results, ${ }^{21-23}$ consistent with our results. The surfactant treatment decreased the shunt fraction probably because of reduced microatelectasis and pulmonary edema, thereby leading to improved ventilation/perfusion mismatch with better oxygenation. ${ }^{24}$ In terms of $\mathrm{PaCO}_{2}$ values, there was no significant difference between the groups. This might be because the warm ischemic injury in the current study was not so severe as it affected a significant change in the value of $\mathrm{PaCO}_{2}$. Herein, we reconfirmed that prerecovery surfactant inhalation during warm ischemia could recondition graft compliance and ventilation inhomogeneity and thus lead to attenuation of I-R injury.

The most important cellular role for oxygenation is ATP synthesis via the mitochondrial electron transport chain. ${ }^{25}$ ATP levels are reportedly considered useful indicators of reperfusion injury. ${ }^{26}$ In this study, the ATP levels at the end of reperfusion were similar to those just after inhalation; this maintenance might be one of the main causes of lung protection against I-R injury.

IL-8 is a potent neutrophil chemotactic factor that promotes neutrophil adhesion, migration, and degranulation. ${ }^{27}$ Fisher et al. have shown that lung transplant patients who died from early lung dysfunction had significantly higher levels of IL-8 in the donor BAL. ${ }^{28}$ TNF- $\alpha$ is a proinflammatory cytokine secreted by a 
number of cells, including macrophages, in response to a variety of stimuli. ${ }^{29}$ Serrick et al. have shown that BAL TNF-a levels significantly increased early after I-R injury. ${ }^{30}$ These observations were consistent with our results. Furthermore, surfactant has anti-inflammatory effects that are accompanied by decreased apoptosis during I-R injury. ${ }^{31}$ Neutrophilic sequestration greatly affects the vulnerability of the lung after I-R injury, ${ }^{32,33}$ and causes tissue damage by adhering to the vasculature, infiltrating local tissues, and releasing superoxides and elastases. ${ }^{33}$ In our study, surfactant inhalation prevented pulmonary edema, hemorrhage, and significantly reduced MPO activity.

Less protein exudation into alveoli might reflect a reduced deterioration of the capillary-endothelial barrier. ${ }^{34}$ In this study, protein leakage in the NS group was significantly higher than that in the SF group; this result correlated to an improvement in the $\mathrm{A}-\mathrm{aDO}$. Serum proteins have been shown to inhibit surfactant function, with this inhibition reportedly concentration dependent. ${ }^{35}$ Thus, massive protein leakage in the NS group could have deteriorated the surfactant function.

Surfactants have been administered to patients with severe primary graft dysfunction ${ }^{13,14}$ and to donor lungs for the prevention of primary graft dysfunction. ${ }^{15}$ Surfactant administration has been said to be relatively safe and non-invasive, but, its use in clinical lung transplantation is still rare owing to the high costs. ${ }^{15}$ In addition, surfactant inhalation has some adverse effects, such as transient desaturation during bronchoscopy for instillation. ${ }^{14}$ Therefore, standard protocols of surfactant therapy have not been established to date. Since the amount of surfactant preparation used in clinical lung transplantation was quite low compared with the use in ARDS, ${ }^{15}$ we investigated the surfactant therapy for lungs 
donated after cardiac death.

Although there are various types of merchandised surfactants available in the world, Surfacten ${ }^{\circledR}$ which we used in the current study is the only one that is powdered in storage and is resolved with solvents just before use. Thus, Surfacten ${ }^{\circledR}$ was shown to be active on use. Furthermore, neither antigenicity nor side effects have been reported when it is used within normal dose limits.

The present study had several limitations. First, the cardiac arrest was induced by intravenous injection of potassium chloride, which was not performed in a clinical setting. We selected this procedure because cardiac arrest was induced uniformly. Second, as there was barely any agonal phase, we plan in the near future to use a setting in which cardiac arrest is induced by disconnection of the mechanical ventilation.

In conclusion, we demonstrated that surfactant inhalation mitigated I-R injury on lungs donated after cardiac death in a canine lung transplantation model. Surfactant inhalation could be a convenient and effective method for improving graft functions in lung transplantation from DCD donors.

\section{Acknowledgements}

SURFACTEN ${ }^{\circledR}$ was kindly provided by Mitsubishi Tanabe Pharma Corporation, Osaka, Japan.

\section{Disclosure statement}

The authors have no conflicts of interest to disclose.

Part of this work was presented at the 32nd annual meeting and scientific 
sessions of the International Society for Heart and Lung Transplantation, April 2012, Prague, Czech Republic. 


\section{Figure legends}

Figure 1

Lung tissue energy levels just after inhalation (A) and 240 min after reperfusion (B) in each group. $\mathrm{TAN}=\mathrm{ATP}+\mathrm{ADP}+\mathrm{AMP} . \mathrm{ATP}$, adenosine triphosphate; ADP, adenosine diphosphate; AMP, adenosine monophosphate; TAN, total adenosine nucleotides. TAN: $* p=0.016$, ATP: ${ }^{p}=0.016$, ADP: $* p=0.047$

Figure 2

Cytokine levels in BAL fluid at 240 min after reperfusion in the NS and the SF groups (A-C). IL-8: ${ }^{*}{ }_{p} p=0.0090$, TNF-a: ${ }^{*} p=0.016$

Figure 3

Macroscopic findings at 240 min after reperfusion in the NS (A) and SF (B) groups.

Figure 4

Histologic findings at 240 min after reperfusion ( $\mathrm{H}-\mathrm{E}$ staining). In the NS group, mild to severe interstitial and alveolar edema is observed in almost all areas, moreover, severe interstitial and alveolar hemorrhage is sporadically observed (A). In the SF group, only slightly interstitial edema is observed in alveoli (B). 


\section{References}

1. Steen S, Sjöberg T, Pierre L, Liao Q, Eriksson L, Algotsson L. Transplantation of lungs from a non-heart-beating donor. Lancet 2001; 357: 825-9.

2. Erasmus ME, Verschuuren EA, Nijkamp DM, Vermeyden JW, van der Bij W. Lung transplantation from nonheparinized category III non-heart-beating donors. A single-centre report. Transplantation 2010; 89: 452-7.

3. De Oliveira NC, Osaki S, Maloney JD, et al. Lung transplantation with donation after cardiac death donors: long-term follow-up in a single center. $\mathrm{J}$ Thorac Cardiovasc Surg 2010; 139: 1306-15.

4. Snell GI, Oto T, Levvey B, et al. Evaluation of techniques for lung transplantation following donation after cardiac death. Ann Thorac Surg 2006; 81: $2014-9$.

5. Gomez-de-Antonio D, Campo-Canaveral JL, Crowley S, et al. Clinical lung transplantation from uncontrolled non-heart-beating donors revisited. J Heart Lung Transplant 2012; 31: 349-53 Feb 3.

6. Chen F, Nakamura T, Fujinaga T, et al. Protective effect of a nebulized beta2-adrenoreceptor agonist in warm ischemic-reperfused rat lungs. Ann Thorac Surg 2006; 82: 465-71.

7. Zhang J, Chen F, Zhao X, et al. Nebulized phosphodiesterase III inhibitor during warm ischemia attenuates pulmonary ischemia-reperfusion injury. J Heart Lung Transplant 2009; 28: 79-84.

8. Brackenbury AM, Puligandla PS, McCaig LA, et al. Evaluation of exogenous surfactant in HCL-induced lung injury. Am J Respir Crit Care Med 2001; 163: 1135-42. 
9. Inci I, Arni S, Acevedo C, et al. Surfactant alterations following donation after cardiac death donor lungs. Transpl Int 2011; 24: 78-84.

10. Spragg RG, Lewis JF, Walmrath HD, et al. Effect of recombinant surfactant protein C-based surfactant on the acute respiratory distress syndrome. N Engl J Med 2004; 351: 884-92.

11. Davidson WJ, Dorscheid D, Spragg R, Schulzer M, Mak E, Ayas NT. Exogenous pulmonary surfactant for the treatment of adult patients with acute respiratory distress syndrome: results of a meta-analysis. Crit Care 2006; 10: R41.

12. Markart P, Ruppert C, Wygrecka M, et al. Patients with ARDS show improvement but not normalisation of alveolar surface activity with surfactant treatment: putative role of neutral lipids. Thorax 2007; 62: 588-94.

13. Strüber M, Cremer J, Harringer W, Hirt SW, Costard-Jäckle A, Haverich A. Nebulized synthetic surfactant in reperfusion injury after single lung transplantation. J Thorac Cardiovasc Surg 1995; 110: 563-4.

14. Kermeen FD, McNeil KD, Fraser JF, et al. Resolution of severe ischemia-reperfusion injury post-lung transplantation after administration of endobronchial surfactant. J Heart Lung Transplant 2007; 26: 850-6.

15. Strüber M, Fischer S, Niedermeyer J, et al. Effects of exogenous surfactant instillation in clinical lung transplantation: a prospective, randomized trial. $\mathrm{J}$ Thorac Cardiovasc Surg 2007; 133: 1620-5.

16. Sakamoto J, Chen F, Yamada T, et al. Effect of preprocurement ventilation on lungs donated after cardiac death in a canine lung transplantation model. Transplantation 2011; 92: 864-870.

17. Chen F, Nakamura T, Wada H. Development of new organ preservation 
solutions in Kyoto University. Yonsei Med J 2004; 45: 1107-14.

18. Macklem PT, Proctor DF, Hogg JC. The stability of peripheral airways. Respir Physiol 1970; 8: 191-203.

19. Stahlman M, Lequire VS, Young WC, et al. Pathophysiology of respiratory distress in newborn lambs. Circulatory, biochemical, and pathological considerations. Am J Dis Child 1964; 108: 375-93.

20. Vilstrup C, Gommers D, Bos JA, Lachmann B, Werner O, Larsson A. Natural surfactant instilled in premature lambs increases lung volume and improves ventilation homogeneity within five minutes. Pediatr Res 1992; 32: 595-9.

21. Hausen B, Rohde R, Hewitt CW, et al. Exogenous surfactant treatment before and after sixteen hours of ischemia in experimental lung transplantation. $\mathrm{J}$ Thorac Cardiovasc Surg 1997; 113: 1050-8.

22. Friedrich I, Börgermann J, Splittgerber FH, et al. Bronchoscopic surfactant administration preserves gas exchange and pulmonary compliance after single lung transplantation in dogs. J Thorac Cardiovasc Surg 2004; 127: 335-43.

23. Erasmus ME, Hofstede GJ, Petersen AH, Haagsman HP, Oetomo SB, Prop J. Effects of early surfactant treatment persisting for one week after lung transplantation in rats. Am J Respir Crit Care Med 1997; 156: 567-72.

24. Sandberg KL, Lindstrom DP, Sjöqvist BA, Parker RA. Cotton RB. Surfactant replacement therapy improves ventilation inhomogeneity in infants with respiratory distress syndrome. Pediatr Pulmonol 1997; 24: 337-43.

25. Jain M, Sznajder JI. Effects of hypoxia on the alveolar epithelium. Proc Am Thorac Soc 2005; 2: 202-5.

26. Hirata T, Fukuse T, Nakamura T, et al. Reperfusion lung injury after cold 
preservation correlates with decreased levels of intrapulmonary high-energy phosphates. Transplantation 2000; 69: 1793-801.

27. Huber AR, Kunkel SL, Todd RF 3rd, Weiss SJ. Regulation of transendothelial neutrophil migration by endogenous interleukin-8. Science 1991; 254: 99-102.

28. Fisher AJ, Donnelly SC, Hirani N, et al. Elevated levels of interleukin-8 in donor lungs is associated with early graft failure after lung transplantation. Am J Respir Crit Care Med 2001; 163: 259-65.

29. Khimenko PL, Bagby GJ, Fuseler J, Taylor AE. Tumor necrosis factor-alpha in ischemia and reperfusion injury in rat lungs. J Appl Physiol 1998; 85: 2005-11.

30. Serrick C, Adoumie R, Giaid A, Shennib H. The early release of interleukin-2, tumor necrosis factor-alpha and interferon-gamma after ischemia reperfusion injury in the lung allograft. Transplantation 1994; 58: 1158-62.

31. van Putte BP, Cobelens PM, van der Kaaij N, et al. Exogenous surfactant attenuation of ischemia-reperfusion injury in the lung through alteration of inflammatory and apoptotic factors. J Thorac Cardiovasc Surg 2009; 137: 824-8.

32. Urabe N, Fujisawa T, Saitoh Y, et al. The capacity of dog lung to release prostaglandin I2 as a biochemical parameter for evaluating lung damage during preservation. Transplantation 1994; 57: 194-8.

33. Barbotin-Larrieu F, Mazmanian M, Baudet B, et al. Prevention of ischemia-reperfusion lung injury by inhaled nitric oxide in neonatal piglets. $\mathrm{J}$ Appl Physiol 1996; 80: 782-8.

34. Kutschka I, Sommer SP, Hohlfeld JM, et al. In-situ topical cooling of lung grafts: early graft function and surfactant analysis in a porcine single lung transplant model. Eur J Cardiothorac Surg 2003; 24: 411-9. 
35. Seeger W, Stöhr G, Wolf HR, Neuhof H. Alteration of surfactant function due to protein leakage: special interaction with fibrin monomer. J Appl Physiol 1985; 58: $326-38$. 
measures analysis of variance. 
Table 1. Assessment of lung and cardiac function in surviving recipients in the NS $(n=5)$ and SF $(n=5)$ groups.

Time after transplantation, min

Before OP

30

75

120

180

240

$P$-value

Dynamic compliance, bilateral lung, $\mathrm{ml} / \mathrm{cmH}_{2} \mathrm{O}$

$\begin{array}{llllllll}\text { NS } & 23.6 \pm 3.3 & 19.0 \pm 1.6 & 13.7 \pm 1.5 & 12.8 \pm 1.9 & 12.8 \pm 1.0 & 11.8 \pm 1.5 & \\ \text { SF } & 22.0 \pm 2.7 & 30.1 \pm 4.8 & 24.0 \pm 3.5 & 21.4 \pm 1.8 & 21.5 \pm 4.2 & 21.3 \pm 3.2 & 0.0003\end{array}$

Dynamic compliance, left lung, $\mathrm{ml} / \mathrm{cmH}_{2} \mathrm{O}$

NS

SF

$7.8 \pm 0.9 \quad 7.7 \pm 1.5$

$\mathrm{PaO} 2, \mathrm{mmHg}$

NS

$$
607.2 \pm 35.9
$$

$569.2 \pm 83.4$

$337.8 \pm 242.5$

$243.4 \pm 192.9$

$132.4 \pm 95.3$

$64.0 \pm 15.0$

SF

$577.2 \pm 31.7$

$626.0 \pm 62.2$

$609.0 \pm 78.6$

$574.2 \pm 128.9$

$541.8 \pm 128.8$

$547.8 \pm 96.2$

0.0022

$\mathrm{PaCO} 2, \mathrm{mmHg}$

$\begin{array}{llllllll}\text { NS } & 20.9 \pm 2.2 & 23.6 \pm 2.0 & 33.8 \pm 9.3 & 39.6 \pm 14.8 & 43.0 \pm 19.0 & 46.8 \pm 17.7 & \\ \text { SF } & 20.7 \pm 2.3 & 21.1 \pm 1.7 & 30.3 \pm 5.3 & 31.4 \pm 6.4 & 34.9 \pm 6.0 & 35.3 \pm 6.2 & 0.27\end{array}$

Mean PAP, mmHg

$\begin{array}{llllllll}\text { NS } & 17.2 \pm 2.6 & 16.8 \pm 2.8 & 44.2 \pm 16.3 & 43.0 \pm 6.2 & 40.8 \pm 5.1 & 39.0 \pm 4.1 \\ \text { SF } & 18.8 \pm 2.5 & 17.6 \pm 2.7 & 40.6 \pm 8.8 & 39.8 \pm 7.9 & 42.2 \pm 6.3 & 41.4 \pm 12.6 & 0.97\end{array}$

Mean CVP, mmHg

$\begin{array}{llllllll}\text { NS } & 4.2 \pm 2.0 & 4.4 \pm 1.7 & 7.2 \pm 2.5 & 7.6 \pm 1.9 & 9.4 \pm 2.6 & 9.8 \pm 3.8 & \\ \text { SF } & 5.6 \pm 1.1 & 5.8 \pm 1.8 & 7.2 \pm 1.6 & 8.0 \pm 1.7 & 8.0 \pm 2.1 & 8.2 \pm 2.2 & 0.98\end{array}$

Mean LAP, mmHg

$\begin{array}{llllllll}\text { NS } & 11.6 \pm 2.9 & 8.4 \pm 2.9 & 4.8 \pm 3.3 & 6.2 \pm 2.6 & 6.6 \pm 2.5 & 7.4 \pm 3.8 & \\ \text { SF } & 12.0 \pm 2.9 & 10.8 \pm 2.8 & 8.8 \pm 1.5 & 9.6 \pm 3.2 & 8.8 \pm 4.1 & 8.2 \pm 2.0 & 0.11\end{array}$

Cardiac output, l/min

\begin{tabular}{|c|c|c|c|c|c|c|}
\hline NS & $0.7 \pm 0.1$ & $0.8 \pm 0.4$ & $0.7 \pm 0.1$ & $0.7 \pm 0.2$ & $0.7 \pm 0.2$ & $0.5 \pm 0.3$ \\
\hline SF & $1.0 \pm 0.2$ & $0.8 \pm 0.2$ & $0.8 \pm 0.3$ & $0.8 \pm 0.3$ & $0.8 \pm 0.2$ & $0.9 \pm 0.3$ \\
\hline
\end{tabular}

PVR, dyn $\cdot s \cdot \mathrm{cm}^{-5} \times 10^{3}$

\begin{tabular}{|c|c|c|c|c|c|c|}
\hline NS & $682.7 \pm 334.1$ & $994.7 \pm 496.5$ & $4813.9 \pm 2124.7$ & $4538.2 \pm 1450.0$ & $4559.4 \pm 2056.5$ & $4581.2 \pm 1793.9$ \\
\hline ᄃ & $557.5 \pm 41.2$ & $707.6 \pm 177.1$ & $3295.9 \pm 742.5$ & $3151.5 \pm 1305.9$ & $3436.9 \pm 1328.9$ & $3049.5 \pm 1031.4$ \\
\hline
\end{tabular}

Shunt fraction, \%

$\begin{array}{llllllll}\text { NS } & 4.7 \pm 3.3 & 9.5 \pm 6.9 & 17.7 \pm 12.0 & 29.2 \pm 20.2 & 38.0 \pm 20.9 & 50.5 \pm 23.7 & \\ \text { SF } & 6.0 \pm 2.1 & 4.4 \pm 3.2 & 4.3 \pm 2.8 & 5.7 \pm 5.9 & 6.7 \pm 4.8 & 7.8 \pm 5.1 & 0.0078\end{array}$

$\mathrm{A}-\mathrm{aDO}_{2}, \mathrm{mmHg}$

\begin{tabular}{llllllll} 
NS & $80.6 \pm 36.5$ & $115.3 \pm 81.3$ & $334.4 \pm 235.9$ & $421.9 \pm 179.9$ & $528.8 \pm 80.6$ & $592.6 \pm 7.6$ & \\
SF & $110.8 \pm 29.7$ & $70.6 \pm 41.6$ & $78.2 \pm 60.1$ & $103.2 \pm 131.7$ & $129.2 \pm 133.6$ & $122.6 \pm 99.6$ & 0.0017 \\
\hline
\end{tabular}

$\mathrm{OP}=$ operation, $\mathrm{PAP}=$ pulmonary artery pressure; $\mathrm{CVP}=$ central venous pressure; $\mathrm{LAP}=$ left atrial pressure; $\mathrm{PVR}=$ pulmonary vascular resistance; $\mathrm{A}-\mathrm{aDO}_{2}=$ alveolar-arterial oxygen pressure difference. Data are shown as mean $\pm \mathrm{SD}$. $\mathrm{p}$-values are for the differences between groups by repeated 
Figure 1
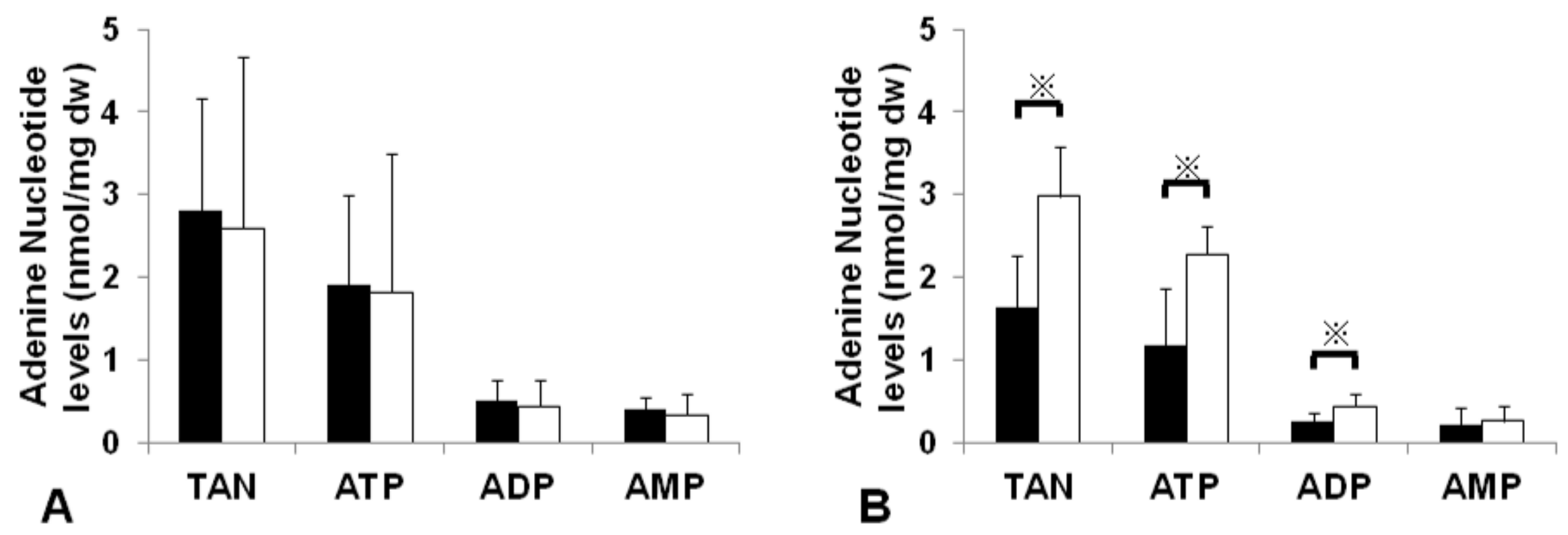
Figure 2
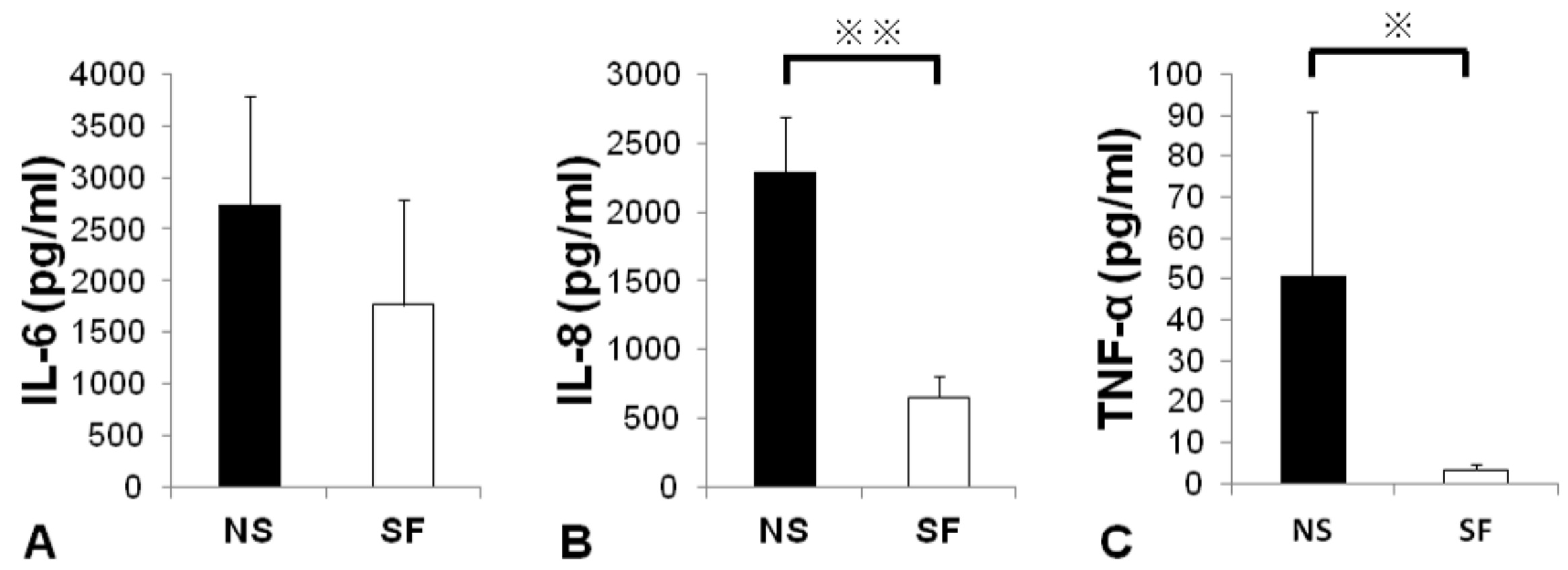
Figure 3
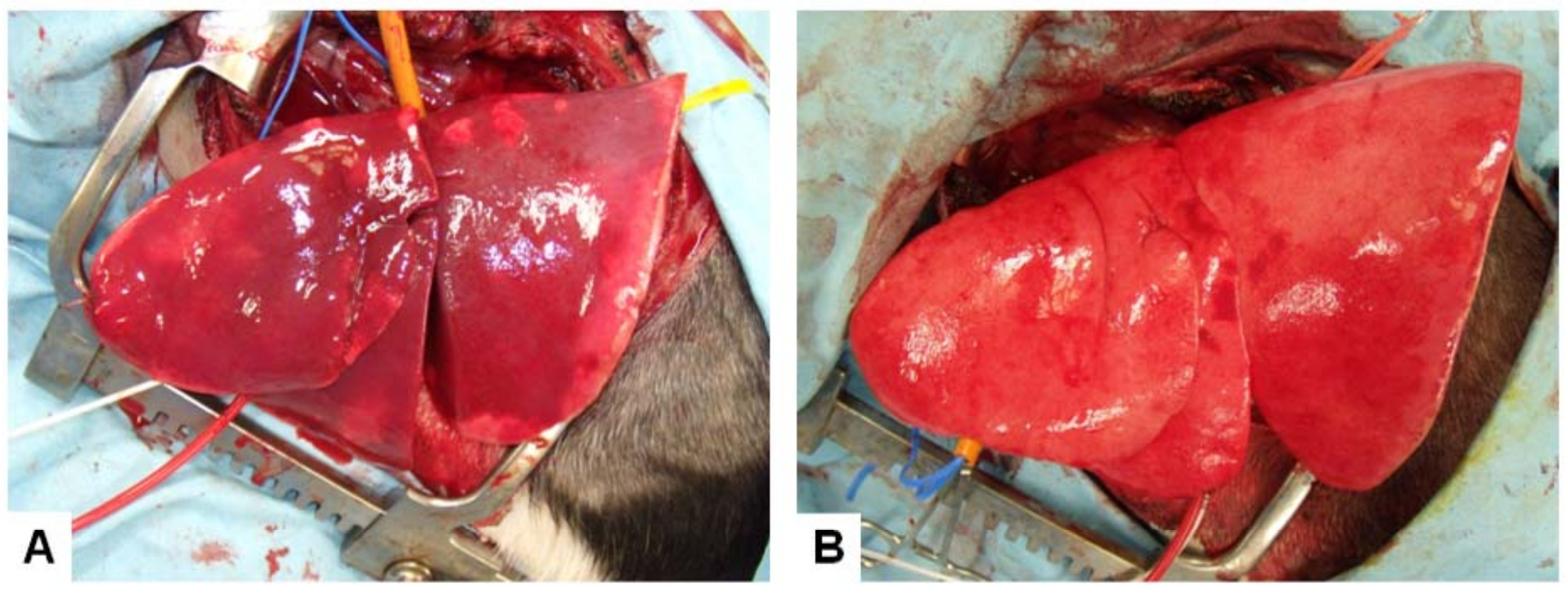
Figure 4
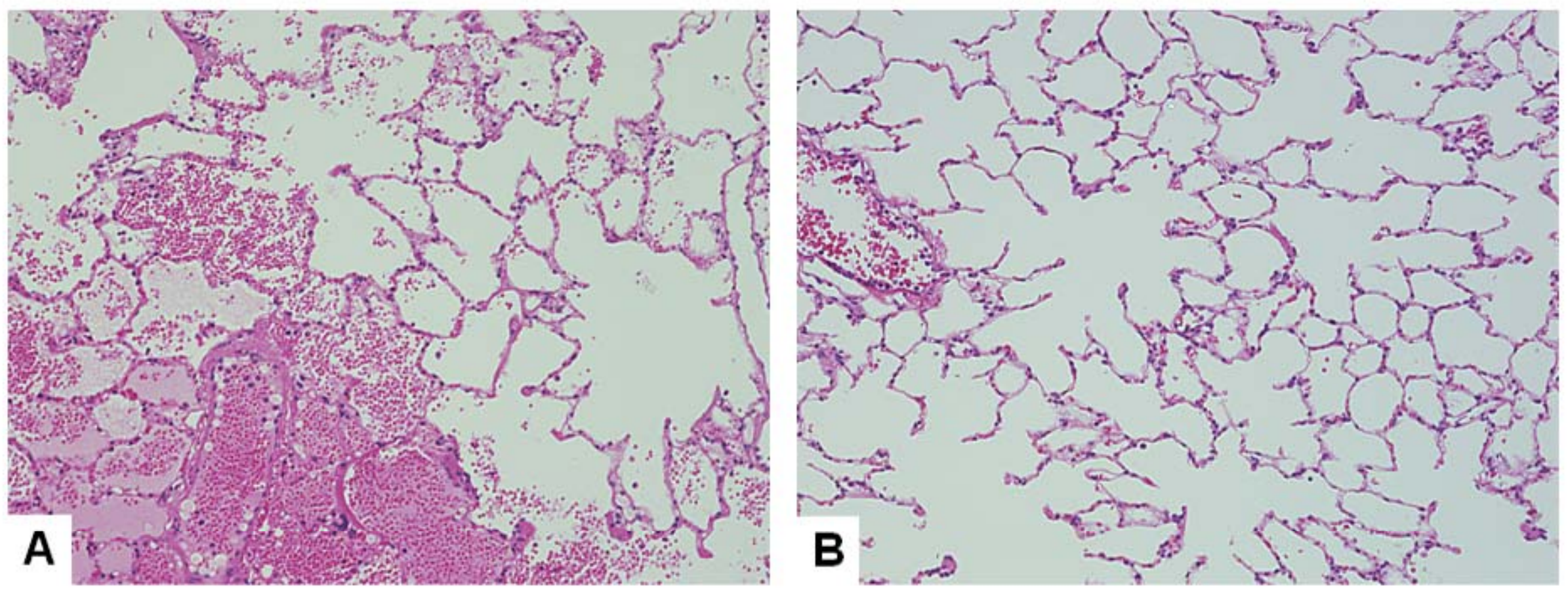